OPEN ACCESS

Edited by:

Paul Enck,

University of Tübingen,

Germany

Reviewed by:

Dimos-Dimitrios D. Mitsikostas, National and Kapodistrian University of Athens Medical School,

Greece

Andrew Geers,

University of Toledo,

United States

*Correspondence:

Magne Arve Flaten

magne.a.flaten@ntnu.no

Specialty section:

This article was submitted to Psychosomatic Medicine,

a section of the journal

Frontiers in Psychiatry

Received: 24 October 2018

Accepted: 29 March 2019

Published: 15 April 2019

Citation:

Daniali $\mathrm{H}$ and Flaten MA

(2019) A Qualitative Systematic

Review of Effects of Provider

Characteristics and Nonverbal

Behavior on Pain, and Placebo and

Nocebo Effects.

Front. Psychiatry 10:242.

doi: 10.3389/fpsyt.2019.00242

\section{A Qualitative Systematic Review of Effects of Provider Characteristics and Nonverbal Behavior on Pain, and Placebo and Nocebo Effects}

\author{
Hojjat Daniali ${ }^{1}$ and Magne Arve Flaten ${ }^{2 *}$ \\ ${ }^{1}$ Department of Humanity Sciences, Shahed University, Tehran, Iran, ${ }^{2}$ Department of Psychology, Norwegian University of \\ Science and Technology, Trondheim, Norway
}

Background: Previous research has indicated that the sex, status, and nonverbal behaviors of experimenters or clinicians can contribute to reported pain, and placebo and nocebo effects in patients or research participants. However, no systematic review has been published.

Objective: The aim of this study was to investigate the effects of experimenter/clinician characteristics and nonverbal behavior on pain, placebo, and nocebo effects.

Methods: Using EmBase, Web of Knowledge, and PubMed databases, several literature searches were conducted to find studies that investigated the effects of the experimenter's/ clinician's sex, status, and nonverbal behaviors on pain, placebo, and nocebo effects.

Results: Thirty-four studies were included, 20 on the effects of characteristics of the experimenter/clinician, 11 on the role of nonverbal behaviors, and 3 on the effects of both nonverbal behaviors and characteristics of experimenters/clinicians on pain and placebo/nocebo effects. There was a tendency for experimenters/clinicians to induce lower pain report in participants of the opposite sex. Furthermore, higher confidence, competence, and professionalism of experimenters/clinicians resulted in lower pain report and higher placebo effects, whereas lower status of experimenters/clinicians such as lower confidence, competence, and professionalism generated higher reported pain and lower placebo effects. Positive nonverbal behaviors (e.g., smiling, strong tone of voice, more eye contact, more leaning toward the patient/participant, and more body gestures) contributed to lower reported pain and higher placebo effects, whereas negative nonverbal behaviors (i.e., no smile, monotonous tone of voice, no eye contact, leaning backward from the participant/patient, and no body gestures) contributed to higher reported pain and nocebo effects.

Conclusion: Characteristics and nonverbal behaviors of experimenters/clinicians contribute to the elicitation and modulation of pain, placebo, and nocebo effects.

Keywords: contextual factors, experimenter characteristics, experimenter sex, clinician sex, nonverbal behavior, placebo effect, nocebo effect, pain 


\section{INTRODUCTION}

The present qualitative review investigated whether the characteristics or nonverbal behavior (NB) of the person administrating painful stimulation affected pain or placebo/ nocebo effects in the research participant. The placebo effect is a psychobiological response that may occur following the application of active and inactive interventions (1). Applying an inactive medication paired with positive information about its analgesic effects can reduce pain (2). Likewise, negative information can reverse the analgesic effect of the medication $(3,4)$ and is called a "nocebo effect" $(5,6)$. Classical conditioning (previous experience with a treatment) and verbal information about the efficacy of the treatment are involved in the induction of placebo effects and expectations, that a treatment will reduce a symptom (e.g., pain), mediate the effects of both processes $(7,8)$.

Expecting that a procedure will increase pain may elicit anxiety and increase pain, whereas expecting that a procedure will decrease pain may reduce anxiety and thus reduce pain (9-12). As noted, placebo effects are induced by verbal information and/ or classical conditioning [e.g., Refs. $(2,4,12-14)]$. However, other factors can modulate the experience of pain and placebo and nocebo effects. Treatments, whether active or sham, are administered in a compound of situational elements such as medication features (e.g., color of a tablet), the healthcare setting (hospital or clinic layout), and the characteristics and behavior of the experimenter/clinician. Such subtle cues in the environment $(7,15,16)$ can affect the treatment outcome. For instance, Levine and Gordon (17) used three different methods of administering an inert substance (injection by a person sitting beside the patient and giving suggestive information; injection by a person in an adjacent room; or an injection by a programmable machine) and showed that even subtle cues that suggest a painkiller was administered could elicit a placebo response.

This systematic review is aimed to focus on the fields of pain and placebo/nocebo effects, due to their large literature background. This review is to our knowledge the first investigation of whether cues such as characteristics and NBs of the experimenter or clinician can affect pain, and placebo and nocebo effects.

\section{Experimenter/Clinician Characteristics}

Characteristics of experimenters/clinicians such as sex or gender contribute to the report of pain (18-21). "Gender" refers to the societal definition of characteristics for each sex and consists of beliefs of proper behaviors including pain behaviors. "Sex" refers to biological sex $(20,22)$. In Western societies, the stereotypical male gender role is characteristically stoic and tries to impress women by their capability to tolerate pain, whereas the female role displays higher sensitivity to pain to induce protective behaviors in men (19). Characteristics of observers or providers can impact the experience of pain (22-25). For instance, Aslaksen et al. (25) indicated that, compared to males tested by a male experimenter, male participants who were tested by a female experimenter reported lower pain. The status of the experimenter/clinician, like the expertise, appearance, and professionalism, is another characteristic that may influence the report of pain or placebo effects (22, 26-31). For instance, Mercer et al. (32) reported that patients perceived clinicians wearing laboratory coats as more professional, whereas clinicians with informal clothes were rated less professional, compared to clinicians with laboratory clothes $(29,32,33)$.

\section{Experimenter or Clinician Nonverbal Behaviors}

NB is present in almost all human interactions and conveys information that may modulate the verbal message. NB is behavior without a linguistic component (34) and refers to expression of thoughts and feelings through nonverbal expressions (35). NBs can be automatic (36) and may gain priority when there is an incongruity between nonverbal and verbal information (37). NB is divided into positive (NBs that convey a positive emotion, attitude, or relationship) and negative (NBs that convey a negative emotion, attitude, or relationship); and into micro-level (e.g., smiling, leaning forward, hand movement, eye contact, tone of voice, and body gesture) and macro-level behaviors (i.e., a collection of micro-level behaviors that conveys a psychological meaning such as dominance, confidence, or warmth) (38). NB contributes to building of relationships, provides signs about unspoken thoughts and emotions, and strengthens or contradicts verbal information (39). Also, the perception of NBs can be nonconscious and automatic $(35,40-43)$. Research suggests that NBs of experimenters/clinicians can modulate pain, and placebo/ nocebo effects [e.g., Refs. $(22,44)]$. For instance, Ambady and Gray (40) demonstrated that clinician's negative NBs, such as lack of smiling, a larger distance from patients, and looking away from them, contributed to decreased cognitive (focused attention and level of consciousness) and physical functioning (walking across a room and getting up from a chair) of patients. Another study indicated that negative NBs of clinicians impacted patient's health outcome as keeping a larger distance, and not looking at patients decreased the satisfaction with the consultation (45).

Thus, the characteristics and NBs of the experimenter/clinician can have consequences for health (3) and a review is therefore warranted. This review investigated 1a) whether experimenters'/ clinicians' sex can impact pain and placebo/nocebo effects, 1b) whether the status of experimenters/clinicians influences pain and placebo/nocebo effects, and 2) whether experimenter/ clinician NBs affect pain and placebo/nocebo effects.

\section{METHODS}

\section{Search Procedure}

Searches in the PubMed, EmBase, and ISI databases (Web of Knowledge) were conducted until September 10, 2018. Table 1 shows the list of Boolean term combinations that were used to search in each database.

\section{Data Extraction}

Data were extracted by the first author (HD). The second author (MF) checked the extracted data. The searches resulted in 3,958 hits. Only experimental (i.e., a causal manipulation following 
TABLE 1 | Search terms used for the database search.

\begin{tabular}{|c|c|c|}
\hline & AND & OR \\
\hline "Nonverbal" & "placebo" & "nocebo" \\
\hline "Nonverbal" & "pain" & \\
\hline "Nonverbal" & "hyperalgesia" & "analgesia" \\
\hline "Contextual factor" & "placebo" & "nocebo" \\
\hline "Contextual factor" & "pain" & \\
\hline "Contextual factor" & "hyperalgesia" & "analgesia" \\
\hline "Situational factor" & "placebo" & "nocebo" \\
\hline "Situational factor" & "pain" & \\
\hline "Situational factor" & "hyperalgesia" & "analgesia" \\
\hline "Context" & "placebo" & "Nocebo" \\
\hline "Context" & "pain" & \\
\hline "Context" & "hyperalgesia" & "analgesia" \\
\hline "Subtle cues" & "placebo" & "nocebo" \\
\hline "Subtle cues" & "pain" & \\
\hline "Subtle cues" & "hyperalgesia" & "analgesia" \\
\hline "Nonspecific factors" & "placebo" & "nocebo" \\
\hline "Nonspecific factors" & "pain" & \\
\hline "Nonspecific factors" & "hyperalgesia" & "analgesia" \\
\hline "Experimenter sex" & "placebo" & "nocebo" \\
\hline "Experimenter sex" & "pain" & \\
\hline "Experimenter sex" & "hyperalgesia" & "analgesia" \\
\hline "Experimenter gender" & "placebo" & "nocebo" \\
\hline "Experimenter gender" & "pain" & \\
\hline "Experimenter gender" & "hyperalgesia" & "analgesia" \\
\hline "Physician sex" & "placebo" & "nocebo" \\
\hline "Physician sex" & "pain" & \\
\hline "Physician sex" & "hyperalgesia" & "analgesia" \\
\hline "Physician gender" & "placebo" & "nocebo" \\
\hline "Physician gender" & "pain" & \\
\hline "Physician gender" & "hyperalgesia" & "analgesia” \\
\hline "Clinician sex" & "placebo" & "nocebo" \\
\hline "Clinician sex" & "pain" & \\
\hline "Clinician sex" & "hyperalgesia" & "analgesia" \\
\hline "Clinician gender" & "placebo" & "nocebo" \\
\hline "Clinician gender" & "pain" & \\
\hline "Clinician gender" & "hyperalgesia" & "analgesia" \\
\hline "Provider gender" & "placebo" & "nocebo" \\
\hline "Provider gender" & "pain" & \\
\hline "Provider gender" & "hyperalgesia" & "analgesia" \\
\hline "Clinician sex" & "placebo" & "nocebo" \\
\hline "Clinician sex" & "pain" & \\
\hline "Clinician sex" & "hyperalgesia" & "analgesia" \\
\hline "Experimenter style" & "placebo" & "nocebo" \\
\hline "Experimenter style" & "pain" & \\
\hline "Experimenter style" & "hyperalgesia" & "analgesia" \\
\hline "Experimenter status" & "placebo" & "nocebo" \\
\hline "Experimenter status" & "pain" & \\
\hline "Experimenter status" & "hyperalgesia" & "analgesia" \\
\hline "Experimenter characteristic" & "placebo" & "nocebo" \\
\hline "Experimenter characteristic" & "pain" & \\
\hline "Experimenter characteristic" & "hyperalgesia" & "analgesia" \\
\hline "Physician status" & "placebo" & "nocebo" \\
\hline "Physician status" & "pain" & \\
\hline "Physician status" & "hyperalgesia" & "analgesia" \\
\hline "Physician style" & "placebo" & "nocebo" \\
\hline "Physician style" & "pain" & \\
\hline "Physician style" & "hyperalgesia" & "analgesia" \\
\hline "Physician characteristic" & "placebo" & "nocebo" \\
\hline "Physician characteristic" & "pain" & \\
\hline "Physician characteristic" & "hyperalgesia" & "analgesia" \\
\hline
\end{tabular}

a random assignment in an experiment or a control group), quasi-experimental (i.e., a manipulation without a priori random assignment), and correlational (i.e., a non-experimental method to measure the relationship between variables) studies that investigated the contribution of characteristics and/or NBs of experimenters/clinicians to placebo, nocebo, and pain were included. Studies with both humans and animals were included and the primary target outcomes were pain report and pain behavior (e.g., pain intensity, sensitivity, threshold, duration, tolerance, unpleasantness, and pain medication use). The secondary target outcomes were symptom severity, improvement rate, mood, quality of life, and treatment expectation. A placebo response was defined as the difference between a group or condition where placebo treatment was administrated with information that the placebo was a painkiller, and a natural history control group or condition where no treatment was provided. Studies were also included if equal amounts of medication were administrated to all participants/patients, but where different types of information (verbal and/or nonverbal) about the drug were presented to different conditions and groups. Studies that reported a placebo response only as the difference between a pretest and a posttest in the same group were excluded. Studies that reported the effects of contextual factors such as group or family membership (e.g., the role of NBs of mothers on children reports of pain), race and ethnicity (e.g., the effects of black experimenter's sex), etc., without distinction from other characteristic of experimenters/ clinicians, were excluded. There were no restrictions regarding the target population of included studies. As the terms "Sex" and "Gender" are inconsistently used in studies, both terms were entered in searches, even though the present review focuses on the effects of sex. There is not a review protocol, but a list of the excluded studies is available by contacting the first author (HD) (Figure 1).

In line with previous studies [e.g., Refs. $(38,40)]$, positive NBs were defined as leaning forward, keeping less distance to the participant or patient, more body gestures, a friendly and warm voice, frequent eye contact, nodding, and smiling. Negative NBs were defined as leaning backward, increased distance to the participant/patient, less body gestures, a cold and flat tone of voice, looking away, and frowning. Thirty-four studies (20 experimental, 11 quasi-experimental, and 3 correlational studies) that reported the effect of experimenters/clinicians characteristics and/or NBs on placebo/nocebo effects or pain were included. Included studies were classified in two tables on the basis of the relativeness to whether characteristics (sex and status) (20 studies, Table 2 ) or NBs (11 studies, Table 3) of the experimenter/clinician. Additionally, three studies were included in both tables as they had investigated both NBs and characteristics of experimenters/clinicians. Studies were classified according to design, number of participants, sample (healthy participants, patients, or animals), type of provider (clinician or experimenter), characteristics (Table 2) or NB (Table 3), target outcome, and the result.

\section{Bias Risk Assessment}

In order to represent trustable outcomes, systematic reviews should acknowledge a number of risk of biases (74). Although there is not a protocol review, the aims of this study did 


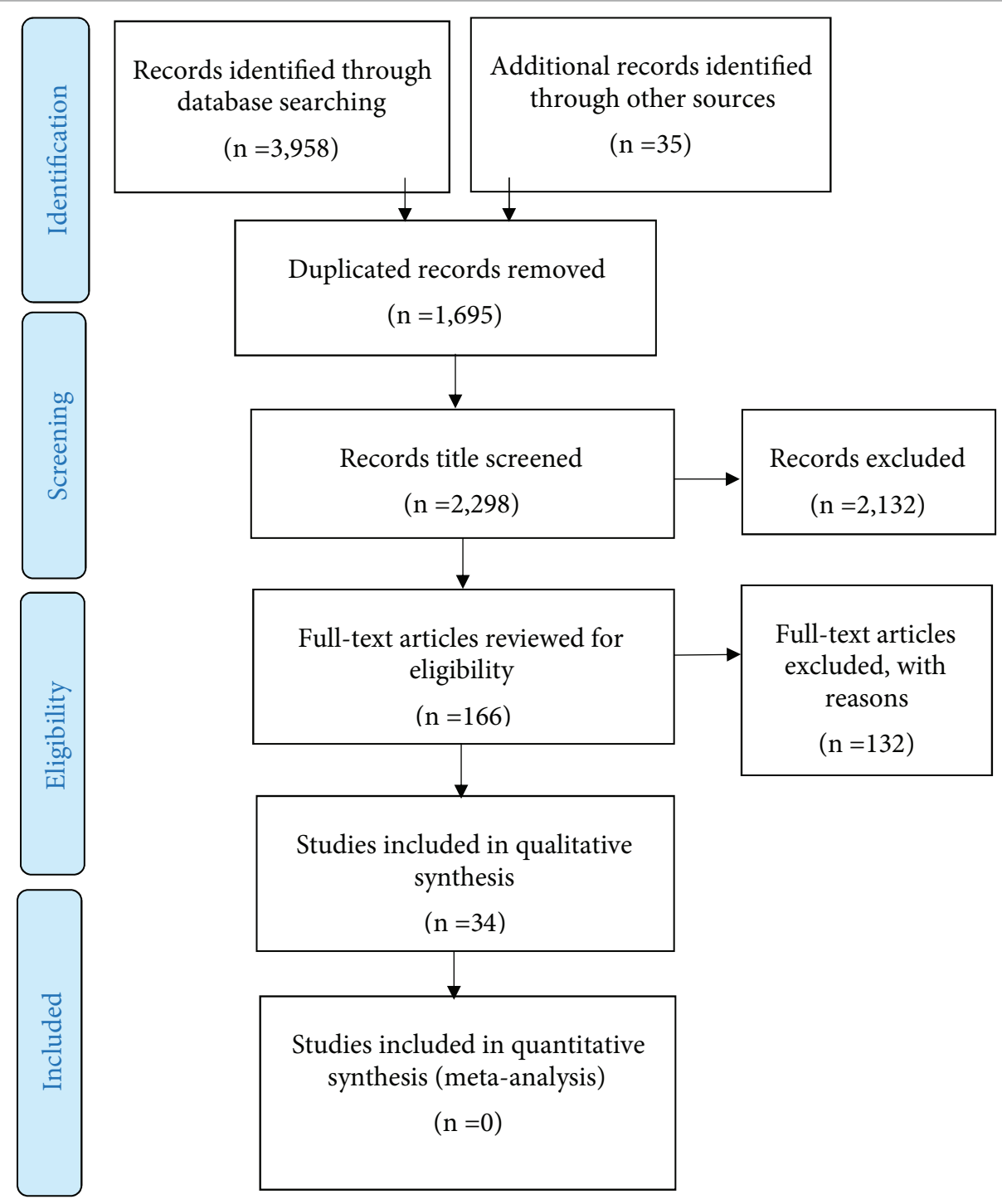

FIGURE 1 | PRISMA flow diagram of steps taken in this review.

not change throughout the study and the risk of reporting bias (i.e., changing the aims according to the nature of obtained findings) was avoided (74). To avoid the risk of evidence selection bias (lack of access to all of the accessible information), the references and citation lists (in google scholar) of all included studies were manually searched and studies that fulfilled the inclusion criteria were entered. Although there is no consensus on what tool to assess the risk of bias in different types of studies, the Cochrane risk of bias tool was used to evaluate the risk of bias in experimental studies that used random assignment and a control group (75). This tool provides a categorized qualitative judgment about the level of risk (high, low, or unknown) across a number of bias types, and includes random sequence generation (i.e., concerning randomization and random sampling), allocation concealment (i.e., hiding the nature of exposure and control groups from participants and personnel), blinding of participants and personnel, blinding of outcome assessment (e.g., the level of objectiveness in outcome assessments), incomplete outcome data (i.e., concerning the missing data and dropouts), selective reporting (i.e., reported and unreported findings), and other biases [for comprehensive information, see Ref. (75)]. To evaluate the risk of bias in quasi-experimental and correlational studies, the Risk of Bias Assessment tool for Non-randomized Studies (RoBANS) was used. RoBANS can be used to assess all study types except for randomized control trials and contains six domains for the risk of bias, which are the selection of participants, confounding variables (i.e., lack of clear distinction between dependent and independent variables), the measurement of exposure (e.g., reliability of measures and scales used), the blinding of outcome assessments, incomplete outcome 


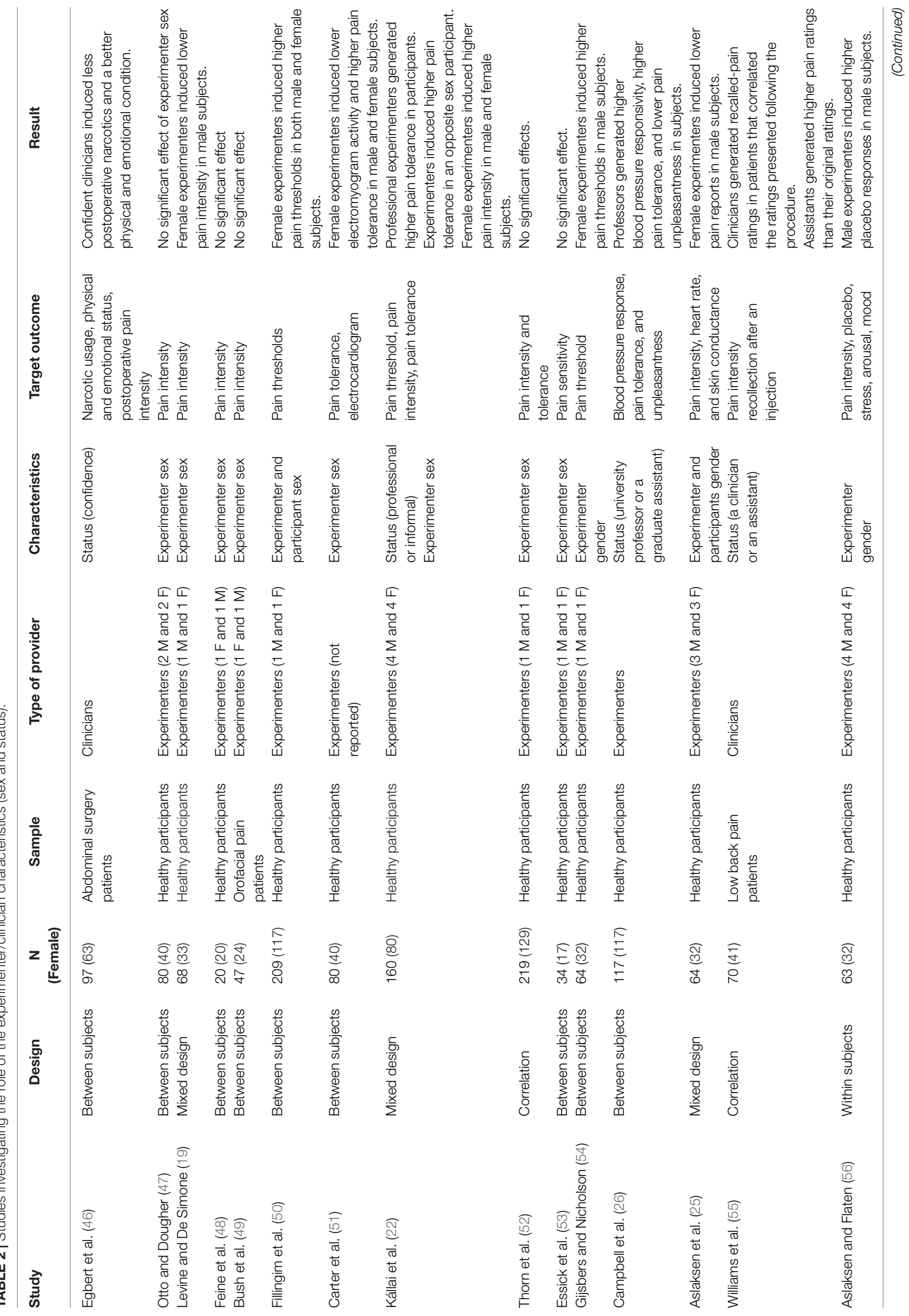




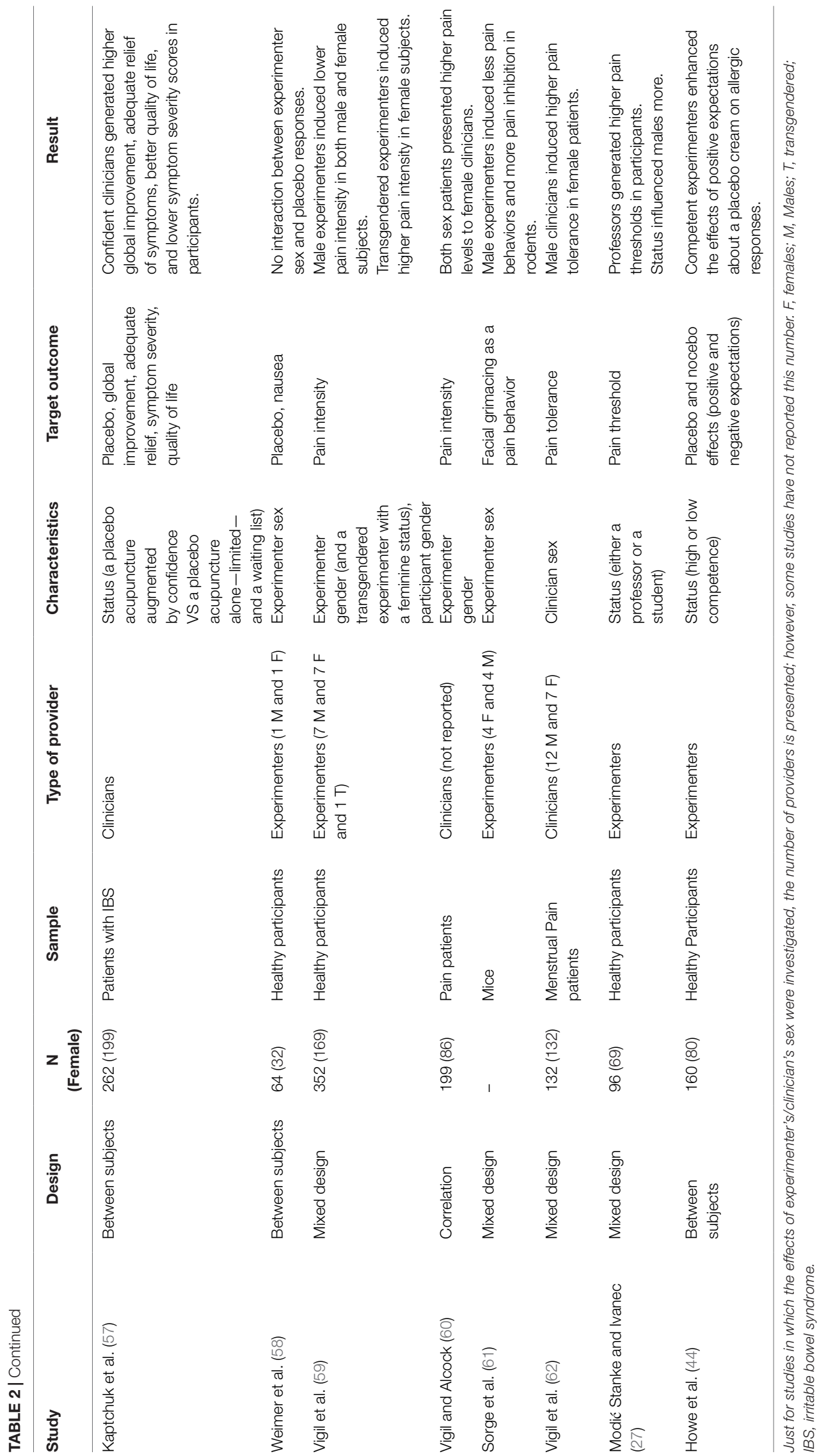




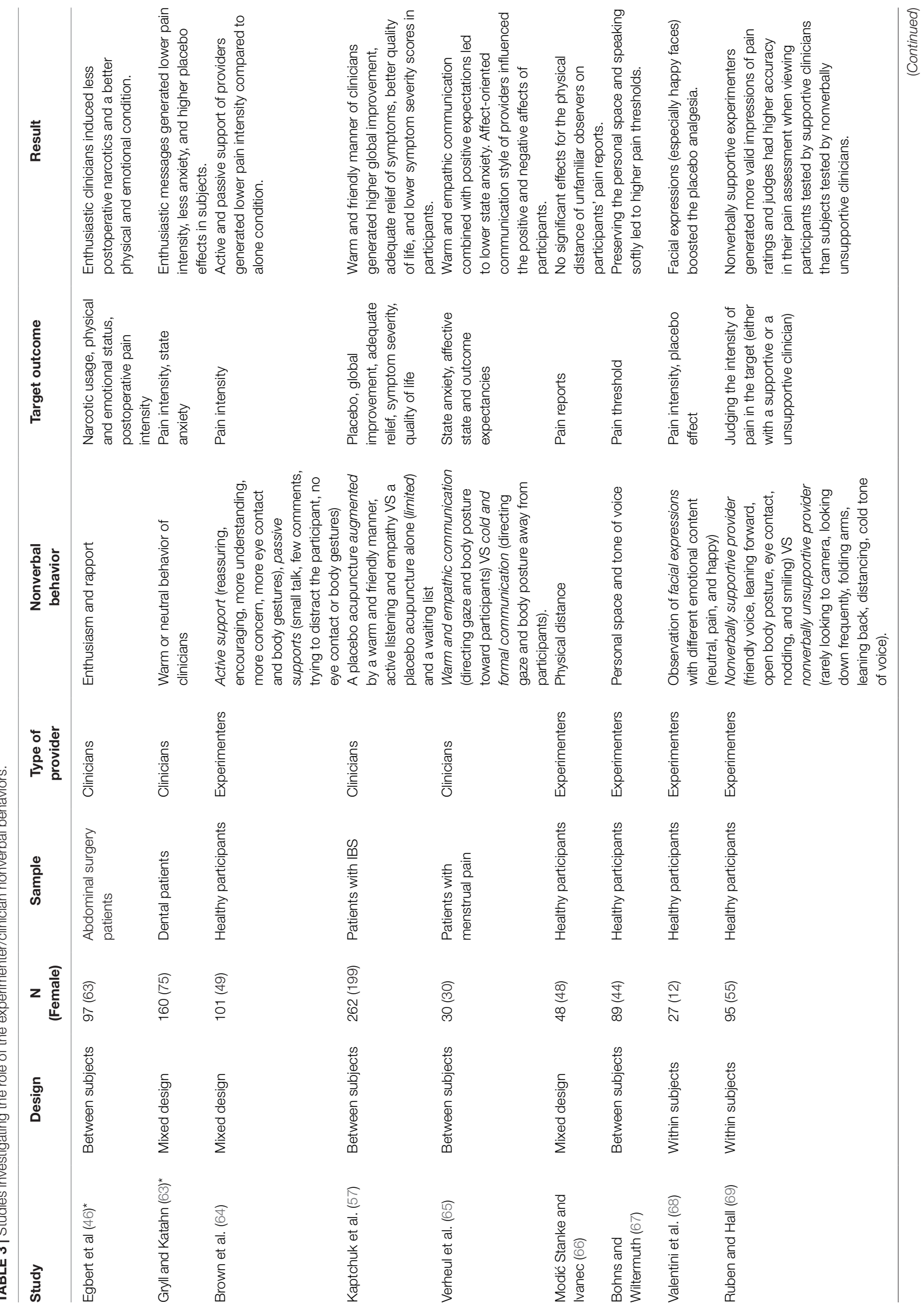




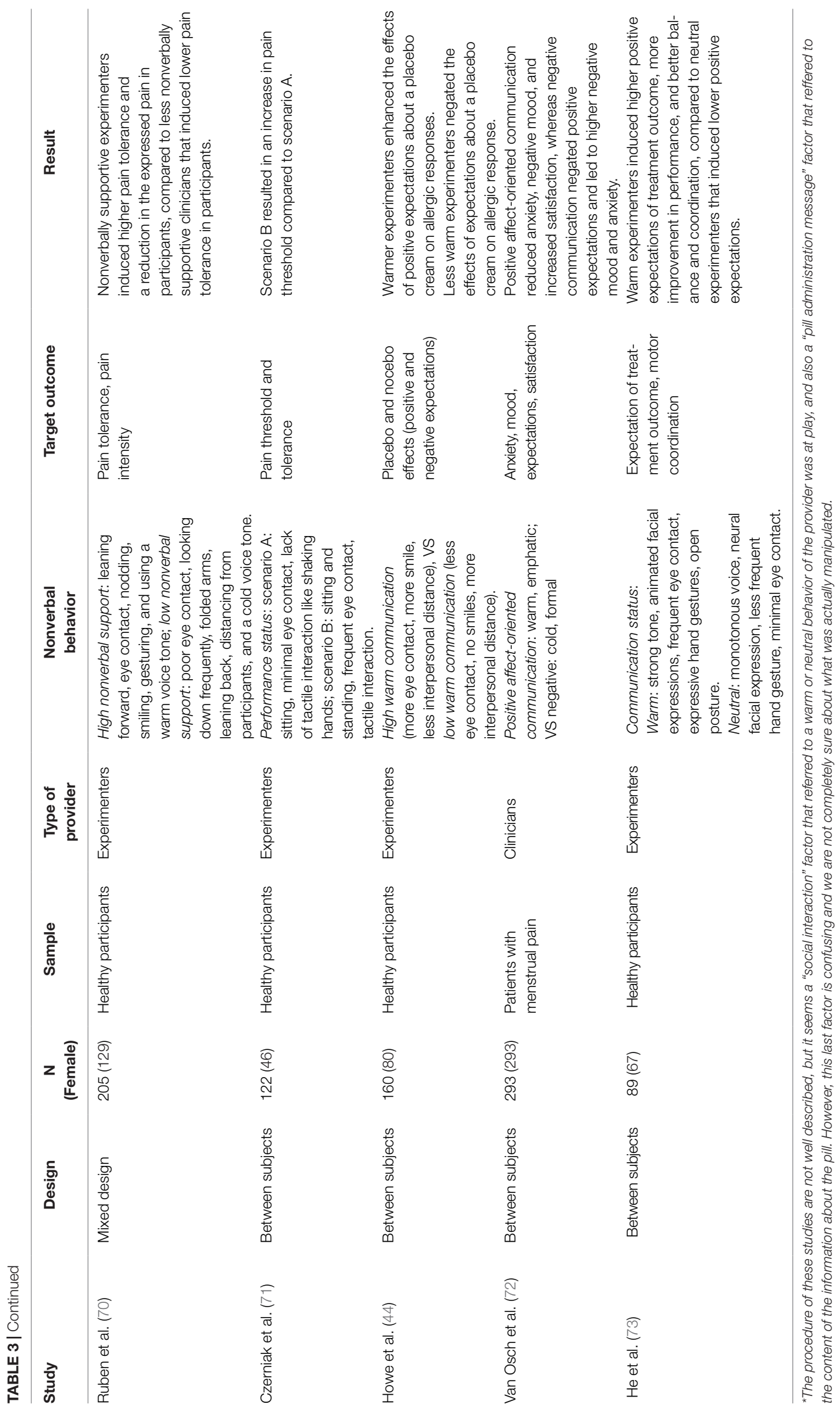


data, and selective outcome reporting. RoBANS is compatible with the Cochrane risk of bias tool and has a same qualitative judgment procedure [for more information, see Ref. (76)].

Using the Cochrane risk of bias assessment tool for experimental studies (75) and RoBANS for quasi-experimental and correlational studies (76), the risk of bias of the individual studies was judged by both authors and the second author (MF) synchronized the results in two tables (Table 5 for Cochrane risk of bias assessment; and Table $\mathbf{6}$ for the RoBANS; see the results).

\section{RESULTS}

A total of 34 studies were identified: 20 on the role characteristics, 11 on the role of NBs, and 3 studies on the role of both characteristics and NBs of the experimenters/clinicians.

\section{Experimenter/Clinician Characteristics Experimenter/Clinician Sex and the Participants' Pain} A total of 15 studies investigated whether the sex of the experimenter/clinician affected the pain report of research participants: Six studies showed a main effect of experimenter sex: three studies showed that male experimenters induced lower pain intensities than females did $(22,59,60)$, and Sorge et al. (61) showed that male experimenters induced less pain behaviors and more pain inhibition in rodents. On the other hand, two studies reported that female experimenters induced lower pain intensities than males $(50,51)$. Nine studies reported no main effect for the sex of the experimenter/clinician (19, 25, 47-49, 52-54, 62) (Table 2).

Ten of these 15 studies investigated the interaction of experimenter and subject sex: Three studies showed that, compared to male experimenters, female experimenters induced higher pain thresholds (54), lower pain intensities $(19,25)$, and marginally significant lower pain unpleasantness (25) in male subjects. Two studies reported that, compared to female experimenters, male experimenters induced higher pain tolerance in female subjects $(22,62)$. On the other hand, five studies did not find a significant interaction of experimenter/ clinician sex and participant sex on pain report $(47,50-53)$. The remaining four studies $(48,49,59,60)$ did not use subject sex as a dependent variable and thus could not investigate the interaction of experimenter/clinician sex and participant/ patient sex. One study was on animals and was not relevant in this context (61) (Table 2).

In sum, there is no reliable tendency for a main effect of experimenter sex on pain. However, there is some evidence of an interactive effect, as 5 of 10 studies show that the experimenter induced less pain in a subject of the opposite sex $(19,22,25,54$, 62) (Table 2).

\section{Experimenter/Clinician Sex and Placebo/Nocebo Effects}

Two studies investigated the role of experimenter/clinician sex on placebo/nocebo effects: Aslaksen and Flaten reported that, compared to female experimenters, male experimenters contributed to higher placebo responses in male subjects (56). However, Weimer et al. (58) who studied the effects of ginger and a placebo on nausea, reported no interaction between experimenter sex and placebo responses (Table 2; for a review, see Table 4).

In sum, there is no reliable tendency for the impact of experimenter sex on placebo effects (Table 2).

\section{Experimenter/Clinician Status and Participants' Pain}

Five studies investigated the effects of experimenter/clinician status on pain reports of research participants: Three studies showed that compared to lower professional status (a student or an assistant), higher-status (e.g., a faculty member or a professor) experimenters generated higher pain thresholds (27) and tolerance $(22,26)$ and lower pain unpleasantness $(26)$. Williams and colleagues (55) reported that in comparison with research assistants, clinicians contributed to more accurate pain ratings (i.e., recollections of pain intensity following a surgery, correlated with pain ratings presented at the time of surgery) in low back pain patients. Also, Egbert et al. (46) reported that confident clinicians had patients with less usage of narcotics and in a better physical and emotional state than patients of less confident clinicians (Table 2).

In sum, all the five studies showed that higher professional status and higher confidence of experimenters/clinicians led to lower pain reports $(22,26,27)$, more accurate pain ratings (55), and better physical and emotional state (46). No studies reported other effects of experimenter/clinician status on pain (Table 2).

\section{Experimenter/Clinician Status and Placebo/Nocebo Effects}

Two studies investigated the effects of the status of experimenters/ clinicians on placebo/nocebo effects: Kaptchuk and colleagues (57) showed that, compared to less confident practitioners, more confident clinicians induced higher symptom relief, higher scores on a global improvement scale, and less symptom severity in patients with irritable bowel syndrome (IBS). Howe et al. (44) reported that competent experimenters (who made no mistakes throughout the experiment) induced higher placebo effects (Table 2).

To sum up, two studies revealed that confidence and competence status of experimenters/clinicians generated higher placebo effects $(44,57)$. No studies reported other effects of experimenter/clinician status on placebo effects (Table 2).

\section{Nonverbal Behaviors Experimenter/Clinician Nonverbal Behaviors and Participants' Pain}

Seven studies investigated the effects of experimenters/clinicians NBs on the pain of research participants: Ruben et al. (70) showed that, compared to clinicians with negative NBs, clinicians with positive NBs induced higher pain tolerance and less pain expressions. In another study, Ruben and colleagues (69) showed that clinicians with positive NBs generated more accurate pain ratings (i.e., consistency between expressions of pain by subjects 
TABLE 4 | An overview of the effects of experimenter/clinician sex on pain and placebo effects.

\begin{tabular}{|c|c|c|c|c|}
\hline & Study & Sex effect & Target & Finding \\
\hline 1 & Otto and Dougher (47) & No effects & Pain & - \\
\hline 2 & Feine et al. (48) & No effects & Pain & - \\
\hline 3 & Bush et al. (49) & No effects & Pain & - \\
\hline 4 & Thorn et al. (52) & No effects & Pain & - \\
\hline 5 & Essick et al. (53) & No effects & Pain & - \\
\hline 6 & Weimer et al. (58) & No effects & Placebo & - \\
\hline 7 & Levine and De Simone (19) & Interaction effect & Pain & Female experimenters induced lower pain reports in males. \\
\hline 8 & Gijsbers and Nicholson (54) & Interaction effect & Pain & Female experimenters induced lower pain reports in males. \\
\hline 9 & Aslaksen et al. (25) & Interaction effect & Pain & Female experimenters induced lower pain reports in males. \\
\hline 10 & Vigil et al. (62) & Interaction effect & Pain & Male experimenters induced lower pain reports in females. \\
\hline 11 & Aslaksen and Flaten (56) & Interaction effect & Placebo & Male experimenters induced lower pain reports in males. \\
\hline $12^{*}$ & Kállai et al. (22) & Interaction effect & Pain & $\begin{array}{l}\text { Opposite sex experimenters induced lower pain reports. } \\
\text { (i.e., females reported higher pain tolerance to male } \\
\text { experimenters) }\end{array}$ \\
\hline 12 & Kállai et al. (22) & Main effect & Pain & $\begin{array}{l}\text { Female experimenters induced higher pain intensity report } \\
\text { in both sex subjects. }\end{array}$ \\
\hline 13 & Vigil et al. (59) & Main effect & Pain & $\begin{array}{l}\text { Male experimenters induced lower pain reports in both sex } \\
\text { subjects. }\end{array}$ \\
\hline 14 & Vigil and Alcock (60) & Main effect & Pain & $\begin{array}{l}\text { Female clinicians generated higher pain reports in both sex } \\
\text { patients. }\end{array}$ \\
\hline 15 & Sorge et al. (61) & Main effect & Pain & $\begin{array}{l}\text { Male experimenters induced lower pain expressions in } \\
\text { mice. }\end{array}$ \\
\hline 16 & Carter et al. (51) & Main effect & Pain & $\begin{array}{l}\text { Female experimenters induced lower pain reports in both } \\
\text { sex subjects. }\end{array}$ \\
\hline 17 & Fillingim et al. (50) & Main effect & Pain & $\begin{array}{l}\text { Female experimenters induced lower pain reports in both } \\
\text { sex subjects. }\end{array}$ \\
\hline
\end{tabular}

*The study of Kállai et al. (22) has reported both interaction and main effects. Therefore, this study is considered twice.

and judgments about pain ratings by observers), compared to clinicians with negative NBs. Czerniak et al. (71) showed that a clinician with restricted movements, minimal eye contact, more typing, and lack of tactile interaction such as shaking hands induced lower pain thresholds in participants. In comparison, a clinician that had more eye contact, more body movements, shook hands with patients, and touched the patients through the examination had patients who displayed higher pain thresholds. Bohns and Wiltermuth (67) showed that preserving the physical space (not getting too close to the participants) and speaking softly led to higher pain thresholds, whereas lack of preserving the physical space and speaking loudly led to lower pain thresholds. On the other hand, Egbert et al. (46) reported that patients who were visited by a more enthusiastic clinician had less usage of narcotics and their surgeons considered them in a better physical and emotional condition and ready to discharge from hospital. Brown et al. (64) reported no significant difference between the pain reports of participants who received "active support" (including more eye contact and body gestures) and "passive support" (lack of eye contact or body gestures). However, both groups had lower pain reports than the "alone" (undergoing the experiment alone) group, suggesting that the NBs of the clinician reduced pain report. Modić Stanke and Ivanec (66), on the other hand, reported that closer physical distance of observers from participants did not have any significant effect on the pain report of participants (Table 3).

In sum, six of seven studies concluded that positive NBs of experimenters/clinicians resulted in lower pain reports $(64,67$,
$70,71)$, more accurate pain ratings (69), and less narcotic use and better physical and emotional state (46), whereas negative NBs led to higher pain reports and lower pain tolerance $(67,70,71)$. On the other hand, one study failed to find a significant effect of experimenters/clinicians NB (66) (Table 3).

\section{Experimenter/Clinician Nonverbal Behaviors and Placebo/Nocebo Effects}

Seven studies investigated the effects of experimenters/clinicians NBs on placebo/nocebo effects: Gryll and Katahn (63) found that enthusiastic messages of clinicians generated higher placebo responses and less anxiety in patients that received dental treatment. Another study showed that, compared to the limited interaction (5-min duration, and a very small talk about the sham injection), an augmented communication style (45-min interaction, including a warm and friendly manner) of clinicians resulted in lower pain intensity reports, higher symptom relief, higher scores on a global improvement scale, and less symptom severity (57); whereas limited communication style of clinicians led to higher pain severity reports, lower scores on the global improvement scale, and less symptom relief and higher symptom severity reports by patients (57). Furthermore, compared to a cold communication style (i.e., directing gaze and body posture away from participants and no empathic remarks), a warm communication style (i.e., gazing at the patient, welcoming in a friendly manner, an open body posture, and adding empathic remarks) of clinicians resulted in positive expectations (expectations of shorter pain duration), decreases in anxiety and 
negative mood, and higher treatment satisfaction in women with menstrual pain $(65,72)$. A cold communication style of clinicians resulted in higher anxiety levels and expectations of longer pain duration in patients $(65,72)$ (Table 3 ).

$\mathrm{He}$ et al. (73) showed that, compared to a neutral communication style (speaking in a monotone voice, neutral facial expressions, less hand movements, and less eye contact), clinicians with a positive communication style (including strong tone of voice, dynamic facial expressions, eye contact, hand gestures, and open body postures) induced stronger positive expectations in a coordination and balance test and believed their coordination ability improved more (Table 3).

Howe et al. (44) showed that, compared to a "low-warmth" clinician who used minimal eye contact, no smiles, and had more distance from participant, a "high-warmth" clinician who used more eye contact, more smiles, and had closer distance enhanced the impact of positive expectations about the effects of an inert cream on their allergic responses, and lowered the allergic reactions. Valentini et al. (68) showed that compared to neutral facial expressions, participants had higher placebo effects when they were exposed to more facial expressions with emotional contents. Interestingly, higher placebo effects were reported when participants observed smiling faces (68) (Table 3).

To sum up, all seven studies reported that positive NBs of experimenters/clinicians enhanced the placebo effects and negative NBs lowered placebo effects or increased nocebo effects $(44,57,63,65,68,72,73)$. There were no studies that indicated other effects of NBs (Table 3 ).

\section{Risk of Bias Assessment}

Of the 20 experimental studies, 19 had low risk of bias in random sequence generation, 16 had low risk of bias in allocation concealment, 12 had unclear risk of bias in blinding of participants and personnel, 16 had low risk of bias in blinding of outcome assessment, 18 had low risk of incomplete outcome data, and 19 had low risk of selective reporting bias (Table 5).

Of the 14 quasi-experimental and correlational studies, 10 studies had low risk of bias in selection of participants, 13 had low risk of confounding variables, 7 had low risk of bias in measuring the exposure, 9 had unclear risk of bias in blinding of outcome assessments, 10 had low risk of incomplete outcome data, and 8 studies had unclear risk of bias in selectively reporting the outcomes (Table 6).

\section{DISCUSSION}

Several findings emerged: 1) Five of 10 studies showed an interactive effect of experimenters and participants' sex such that experimenters induced less pain in a participant of the opposite sex. There was, on the other hand, no reliable main effect of experimenter sex on the reports of pain. 2) All five studies showed that experimenters/clinicians of a higher status and confidence induced less pain in participants or had patients who had less narcotic usage. 3) Two of two studies showed that experimenters
TABLE 5 | Cochrane Risk of bias assessment for experimental studies of the effects of experimenters/clinicians characteristics and non-verbal behaviors on pain and placebo effects.

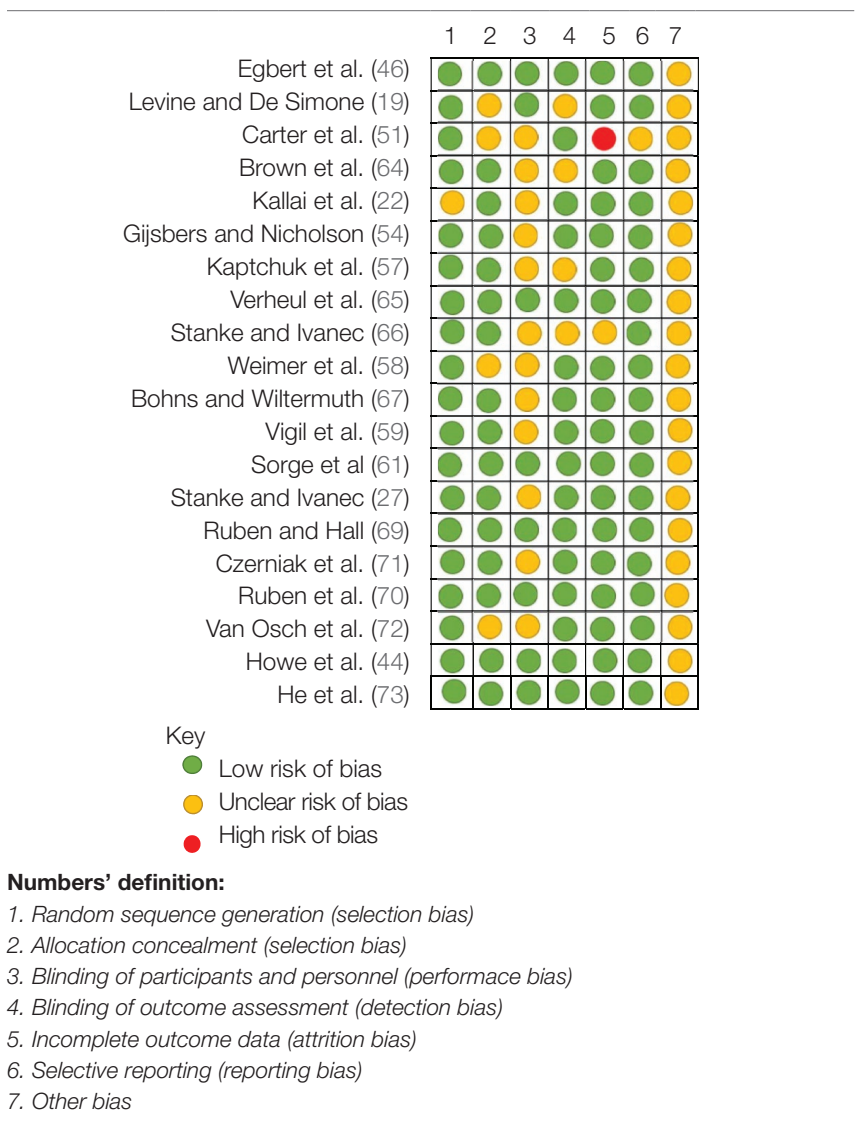

of a high status induced larger placebo effects. 4) Six of seven studies showed that positive NBs induced less pain. 5) All seven studies showed that positive NBs induced larger placebo responses. 6) All seven studies showed that negative NBs induced lower placebo responses or higher nocebo effects.

\section{The Role of Experimenter/Clinician Sex on Pain and Placebo Effects}

Five of 10 studies showed that participants reported lower pain when tested by an experimenter of the opposite sex. Thus, the tendency of an interaction of experimenter/clinician sex and the sex of the participant must be considered with caution. Previous studies have suggested that this tendency can be related to the experimenter gender role rather than to biological factors. For instance, Aslaksen et al. (25) showed that although female experimenters contributed to lower pain report in male subjects, the female experimenters did not have a significant effect on the heart rate variability of the subjects. Thus, the impact of the pain stimulus on autonomic nervous system activity was the same in both male and female participants. This suggests that the lower reported pain in males tested by a female was a reporting bias. In the same line, Flaten et al. (2) showed that female experimenters induced lower pain reports in male participants and concluded 
TABLE 6 | Risk of Bias Assessment for quasi-experimental and correlational studies (RoBANS) of the effects of experimenters/clinicians characteristics and non-verbal behaviors on pain and placebo effects.

Gryll and Katahn (63)
Otto et al. (47)
Feine et al. (48)
Bush et al. (49)

that this could be due to a response bias in males, so they were trying to impress female experimenters by reporting lower pain. Interestingly, Gijsbers and Nicholson (54) showed that by exaggerating the gender-related appearance and behaviors of female experimenters, the hypoalgesic effect of female experimenters on male subjects can be enlarged.

Two studies $(22,62)$ showed that male experimenter/clinicians induced lower pain reports in female subjects. This finding contradicts the conventional gender role assumptions that assumed a helpless state for females, in which they display higher pain to induce male protection. Kállai et al. (22) showed that females reported lower pain to male experimenters and concluded that females, as well as males, try to impress opposite sex experimenters by their ability to tolerate pain longer. This can be due to changes in the female gender role in contemporary societies in which more authority and power are granted for females.

A second explanation attributes the hypoalgesic effects of male experimenters on female subjects to the physiological aspects of females. Vigil et al. (62) tested two groups of high- and low-fertility females by male and female experimenters and showed that, compared to females who were tested by a female experimenter, high-fertility females who were tested by a male experimenter reported lower pain. This finding suggests that physiological factors can contribute to the lower pain reports of female subjects to male experimenters/clinicians. Also, this finding can partially explain why some studies [e.g., Ref. (25)] failed to observe a hypoalgesic effect of male experimenters on female subjects.

There was no reliable effect of experimenter/clinician sex on placebo analgesia $(56,58)$.

\section{The Role of Experimenter/Clinician Status on Pain and Placebo Effects}

Five studies showed that higher status of experimenters/ clinicians generated lower pain reports. Campbell et al. (26) demonstrated that subjects displayed higher blood pressure reactivity and pain tolerance to higher-status experimenters and concluded that increased blood pressure stimulated pressure receptors in the vasculature that also modulate the perception of pain (77-84). The stress induced by the higher-status experimenters may therefore lead to lower pain reports (26).

Two studies demonstrated that higher status of the experimenters/clinicians induced larger placebo effects. Howe et al. (44) showed that competent clinicians enhanced the effects of positive expectations and reduced subject's allergic responses. They suggested that outcome expectations, that are underlying factors for the placebo and nocebo effects, can be modulated by the warmth and competence of clinicians. Notably, Howe et al. (44) studied the effects of low-competence characteristics of clinicians on negative expectations, and did not observe a significant effect on negative expectations.

\section{The Role of Experimenter/Clinician Nonverbal Behaviors on Pain and Placebo Effects}

Six studies showed that positive NBs of experimenters/clinicians induced lower pain reports, and three studies showed that negative NBs resulted in higher pain reports. Pain is recognized as a stressor and most of painful situations induce stress and negative emotions $(54,85)$. Negative emotions and stress can increase the experience of pain [e.g., Refs. $(56,85)]$, whereas providing information about the forthcoming intervention and outcomes of a treatment may reduce the stress and negative emotions. As there can be uncertainty about the outcome of interventions $(54,85)$, participants/patients might use as much of accessible information as possible to gain knowledge about the efficacy of the intervention. NBs of experimenters/clinicians can be a substantial source of information for participants/patients $(36,69,70)$. In this line, Ambady and Gray (40) showed that positive NBs of clinicians (e.g., facial expressiveness, nodding, and smiling) were associated with long-term improvements in cognitive and physical functioning of elderly patients. Previous studies have shown that clients can perceive the expectations of their providers [e.g., Refs. $(36,86)]$. As interpersonal expectations are mostly communicated through NBs [e.g., Ref. (38)], positive NBs of experimenters/clinicians can be interpreted as a sign of satisfactory functioning or results and lead to decrease in negative emotions and subsequently lower pain reports, whereas negative NBs can be assumed as a sign of negative forthcoming results and lead to higher pain reports. In this line, Egbert et al. (46) showed that patients who were exposed to enthusiastic clinicians were in a better emotional state, and Gryll and Katahn (63) showed that enthusiasm by clinicians reduced negative emotions.

Seven studies showed that positive NBs of experimenters/ clinicians induced higher placebo effects, whereas negative NBs 
led to lower placebo effects and higher nocebo hyperalgesia. To explain the modulatory effects of NBs on placebo and nocebo effects, a similar perspective is taken. NBs may have a confirmatory (or contradictory) role for verbal information that is used to induce positive outcome expectations and placebo effects. So, positive NBs may have an additive value for the verbal information, e.g., that a tablet is a powerful pain killer, and negative NBs may contradict the verbal information and diminish the induction of placebo effects. In this line, Howe et al. (44) showed that positive NBs of clinicians enhanced the impact of positive expectations about the effects of an inert cream on allergic responses; and $\mathrm{He}$ et al. (73) showed that positive NBs of clinicians induced stronger positive expectations in a coordination and balance test. Expectations may also contribute to the modulation of emotions and stress. For instance, Verheul et al. (65) and Van Osch et al. (72) reported that positive NBs of clinicians enhanced positive outcome expectancies and reduced the state anxiety and negative mood, whereas negative NBs resulted in higher anxiety levels and expectations of longer pain duration.

Therefore, NBs may have an additive value for the role of verbal information in modulation of expectations, negative emotions, and stress, and hence lead to changes in amplitudes of placebo or nocebo effects. Several studies have reported failure to elicit a placebo effect [e.g., Refs. $(58,87)]$. Uncontrolled NBs of experimenters/clinicians may partially account for such diversity in findings.

\section{CONCLUSION}

This qualitative review documented the contribution of experimenters/clinicians' sex, status, and NBs, as three factors capable of altering the perception of pain, and amplitude of placebo/nocebo effects and responses.

Sex, status, and NBs of experimenters/clinicians are interwoven in every laboratory and clinical setting and the present review shows that these factors can influence research results. The failure to control for the effects of characteristics and NBs of experimenters/clinicians can explain why placebo studies occasionally yield inconsistent or variable findings [e.g., Refs. $(58,87,88)]$, or why the reliability of pain measurement is limited and doubted [e.g., Ref. (25)]. To gain a deeper understanding of the effects of such nonspecific factors, this review emphasizes the need to further investigate the contribution of characteristics and NBs of experimenters/ clinicians in pain and placebo effects.

\section{Recommendations for Future Research}

Prospective investigations are encouraged to address the following gaps in current literature; first, to our knowledge, just two studies have investigated the separate effects of different NBs on pain and placebo effects $(68,73)$. Thus, future studies should specify what specific NBs (facial expressions, eye contact, nodding, physical distance, tone of voice, or body postures) that have the strongest impact on pain and placebo/nocebo effects; He et al. (73) showed that compared to physical distance and body posture, facial expressions and tone of voice had stronger effects on placebo effects. However, this finding should be replicated especially in prospective pain studies. Second, the interaction of NBs and sex of providers and subjects should be investigated to see whether NBs of experimenters can modulate the effects of sex or vice versa. Only one study has studied this and reported that positive NBs of experimenters induced lower pain reports in male subjects than in female subjects (70). Third, future studies should suggest how to control for the effects of NBs in research on pain and other symptoms. Indeed, this can only be achieved if we have more knowledge about the effects of each specific NB on pain or other symptoms. Fourth, studies could consider the effects of other genders (e.g., transgendered experimenters) on the experience of pain; to our knowledge, only one study has addressed this (59) and showed that compared to a male or female experimenter who acted in accordance with their sex, a biological male who acted in a feminine way induced higher pain reports in female subjects. Fifth, there might be an interaction between experimenters/ clinician's sex and their status. Several studies have reported that for example, male providers were considered more credible (87); their status influenced male subjects more (27); male clinicians who were reputed for their expertise were more preferred over female clinicians; and female clinicians who were reputed for their interpersonal skills were preferred more by patients (30). The possible interaction of the status and the sex of the experimenters/clinicians should be taken into account to determine whether status can modulate the effects of sex or vice versa. According to our searches, only Kállai et al. (22) have tested both sex and status systematically, but unfortunately have not reported the interaction of sex and status of the experimenters. Lastly, the underlying mechanisms (e.g., expectations and emotions) of the effects of NBs and characteristics of experimenters/clinicians on pain and placebo effects are still unclear and should be investigated. More knowledge of these factors would be highly relevant in the training of health personnel.

\section{LIMITATIONS}

The present study contains a number of limitations that should be noted here. First is the qualitative nature of this study that hinders the generality of findings. Second is the heterogeneity of keywords used in different studies, which made it difficult to gain access to all related studies and may have caused to miss a few studies; however, to prevent this, several Boolean searches were conducted and also the reference and citation lists of included studies were checked. Third is the interpretation of the findings on the interaction of the experimenters'/ clinicians' sex and subjects' sex. Of the included studies, five studies showed an interaction, and five studies did not find an interaction. Therefore, the findings on the interaction of the experimenter/clinician and participant's sex should be interpreted with caution. Fourth is the problem of confounding 
in some findings such as investigating the provider status and NBs simultaneously and without differentiation as in Kaptchuk et al. (57); or lack of clarity in methodological procedures such as absence of differentiation in providers' sex and status as in Campbell et al. [Ref. (26) or (87)]; or lack of differentiation between verbal and nonverbal components as in Gryll and Katahn (63). Such deficiencies limit the drawing of straightforward conclusions. Additionally, this systematic review did not comprise a review protocol, but authors tried to precisely characterize the scientific nature of this systematic review by determining a priori question and the procedure relevant to the questions.

\section{REFERENCES}

1. Savvas SM, Zelencich LM, Gibson SJ. Should placebo be used routinely for chronic pain in older people? Maturitas (2014) 79(4):389-400. doi: 10.1016/ j.maturitas.2014.09.006

2. Flaten MA, Aslaksen PM, Finset A, Simonsen T, Johansen O. Cognitive and emotional factors in placebo analgesia. J Psychosom Res (2006) 61(1):81-9. doi: 10.1016/j.jpsychores.2005.12.004

3. Aslaksen PM, Lyby PS. Fear of pain potentiates nocebo hyperalgesia. J Pain Res (2015) 8:703. doi: 10.2147/JPR.S91923

4. Flaten MA, Simonsen T, Olsen H. Drug-related information generates placebo and nocebo responses that modify the drug response. Psychosom Med (1999) 61(2):250-5. doi: 10.1097/00006842-199903000-00018

5. Varelmann D, Pancaro C, Cappiello EC, Camann WR. Nocebo-induced hyperalgesia during local anesthetic injection. Anesth Analg (2010) 110(3):868-70. doi: 10.1213/ANE.0b013e3181cc5727

6. Carlino E, Benedetti F. Different contexts, different pains, different experiences. Neuroscience (2016) 338:19-26. doi: 10.1016/j.neuroscience. 2016.01.053

7. Benedetti F. Placebo and the new physiology of the doctor-patient relationship. Physiol Rev (2013) 93(3):1207-46. doi: 10.1152/physrev.00043.2012

8. Benedetti F, Durando J, Vighetti S. Nocebo and placebo modulation of hypobaric hypoxia headache involves the cyclooxygenase-prostaglandins pathway. Pain ${ }^{\circledR}$ (2014) 155(5):921-8. doi: 10.1016/j.pain.2014.01.016

9. Flaten MA, Aslaksen PM, Lyby PS, Bjørkedal E. The relation of emotions to placebo responses. Philos Trans R Soc Lond B Biol Sci (2011) 366(1572):181827. doi: $10.1098 /$ rstb.2010.0407

10. Al'Absi M, Flaten MA. Stress and pain: conclusions and future directions. In: Al'Absi M Flaten MA, editors. The neuroscience of pain, stress, and emotion. United States: Academic Press (2016). p. 283-9. doi: 10.1016/ B978-0-12-800538-5.00013-3

11. Flaten M, Aslaksen P, Lyby P. Positive and negative emotion and placebo analgesia. In: Colloca L, Flaten MA, Meissner K, editors. Placebo and pain: from bench to bedside. United States: Academic Press (2013). p. 72-81. doi: 10.1016/B978-0-12-397928-5.00008-8

12. Colloca L. How placebo responses are formed. In: Colloca L, Flaten MA, Meissner K, editors. Placebo and pain: from bench to bedside. United States: Academic Press (2013). p. 137-48. doi: 10.1016/B978-0-12-397928-5.00014-3

13. Meissner K, Bingel U, Colloca L, Wager TD, Watson A, Flaten MA. The placebo effect: advances from different methodological approaches. J Neurosci (2011) 31(45):16117-24. doi: 10.1523/JNEUROSCI. 4099-11.2011

14. Pollo A, Amanzio M, Arslanian A, Casadio C, Maggi G, Benedetti F. Response expectancies in placebo analgesia and their clinical relevance. Pain (2001) 93(1):77-84. doi: 10.1016/S0304-3959(01)00296-2

15. Di Blasi Z, Harkness E, Ernst E, Georgiou A, Kleijnen J. Influence of context effects on health outcomes: a systematic review. Lancet (2001) 357:757-62. doi: 10.1016/S0140-6736(00)04169-6

16. Kaptchuk TJ. The placebo effect in alternative medicine: can the performance of a healing ritual have clinical significance? Ann Intern Med (2002) 136(11):817-25. doi: 10.7326/0003-4819-136-11-200206040-00011

\section{AUTHOR CONTRIBUTIONS}

MF planned the study. HD searched and extracted the articles and MF screened them. Both authors significantly contributed to the analyses of results, drafting of the manuscript, and preparation of the final draft.

\section{FUNDING}

The present research was funded by the Norwegian University of Science and Technology (NTNU).

17. Levine JD, Gordon NC. Influence of the method of drug administration on analgesic response. Nature (1984) 312(5996):755. doi: 10.1038/312755a0

18. Robinson ME, Wise EA. Gender bias in the observation of experimental pain. Pain (2003) 104(1-2):259-64. doi: 10.1016/S0304-3959(03)00014-9

19. Levine FM, De Simone LL. The effects of experimenter gender on pain report in male and female subjects. Pain (1991) 44(1):69-72. doi: 10.1016/0304-3959(91)90149-R

20. Sanford SD, Kersh BC, Thorn BE, Rich MA, Ward LC. Psychosocial mediators of sex differences in pain responsivity. J Pain (2002) 3(1):58-64. doi: 10.1054/jpai.2002.xb30066

21. Weisse CS, Foster KK, Fisher EA. The influence of experimenter gender and race on pain reporting: does racial or gender concordance matter? Pain Med (2005) 6(1):80-7. doi: 10.1111/j.1526-4637.2005.05004.x

22. Kállai I, Barke A, Voss U. The effects of experimenter characteristics on pain reports in women and men. Pain (2004) 112(1-2):142-7. doi: 10.1016/ j.pain.2004.08.008

23. Vervoort T, Goubert L, Eccleston C, Verhoeven K, De Clercq A, Buysse A, et al. The effects of parental presence upon the facial expression of pain: the moderating role of child pain catastrophizing. Pain (2008) 138(2):277-85. doi: $10.1016 /$ j.pain.2007.12.013

24. Burns JW, Post KM, Smith DA, Porter LS, Buvanendran A, Fras AM, et al. Spouse criticism and hostility during marital interaction: effects on pain intensity and behaviors among individuals with chronic low back pain. Pain (2018) 159(1):25-32. doi: 10.1097/j.pain.0000000000001037

25. Aslaksen PM, Myrbakk IN, Høifødt RS, Flaten MA. The effect of experimenter gender on autonomic and subjective responses to pain stimuli. Pain (2007) 129(3):260-8. doi: 10.1016/j.pain.2006.10.011

26. Campbell TS, Holder MD, France CR. The effects of experimenter status and cardiovascular reactivity on pain reports. Pain (2006) 125(3):264-9. doi: 10.1016/j.pain.2006.06.002

27. Modić-Stanke K, Ivanec D. Pain threshold: measure of pain sensitivity or social behavior? Psihologija (2016) 49(1):37-50. doi: 10.2298/PSI1601037M

28. Testa M, Rossettini G. Enhance placebo, avoid nocebo: how contextual factors affect physiotherapy outcomes. Man Ther (2016) 24:65-74. doi: 10.1016/j.math.2016.04.006

29. Hush JM, Cameron K, Mackey M. Patient satisfaction with musculoskeletal physical therapy care: a systematic review. Phys Ther (2011) 91(1):25-36. doi: 10.2522/ptj.20100061

30. Bishop FL, Smith R, Lewith GT. Patient preferences for technical skills versus interpersonal skills in chiropractors and physiotherapists treating low back pain. Fam Pract (2012) 30(2):197-203. doi: 10.1093/fampra/cms066

31. O’keeffe M, Cullinane P, Hurley J, Leahy I, Bunzli S, O'sullivan PB, et al. What influences patient-therapist interactions in musculoskeletal physical therapy? Qualitative systematic review and meta-synthesis. Phys Ther (2016) 96(5):609-22. doi: 10.2522/ptj.20150240

32. Mercer E, MacKay-Lyons M, Conway N, Flynn J, Mercer C. Perceptions of outpatients regarding the attire of physiotherapists. Physiother Can (2008) 60(4):349-57. doi: 10.3138/physio.60.4.349

33. Petrilli CM, Mack M, Petrilli JJ, Hickner A, Saint S, Chopra V. Understanding the role of physician attire on patient perceptions: a systematic review of the literature-targeting attire to improve likelihood of rapport 
(TAILOR) investigators. BMJ Open (2015) 5(1):e006578. doi: 10.1136/ bmjopen-2014-006578

34. Bänziger T, Grandjean D, Scherer KR. Emotion recognition from expressions in face, voice, and body: the Multimodal Emotion Recognition Test (MERT). Emotion (2009) 9(5):691. doi: 10.1037/a0017088

35. DePaulo BM, Friedman HS. Nonverbal communication. In: Gilbert D, Fiske ST, Lindzey G, editors. Handbook of social psychology. 4th ed. New York: McGraw - Hill (1998). p. 3-40.

36. Belin P, Fillion-Bilodeau S, Gosselin F. The Montreal Affective Voices: a validated set of nonverbal affect bursts for research on auditory affective processing. Behav Res Methods (2008) 40(2):531-9. doi: 10.3758/BRM.40.2.531

37. Jacob H, Kreifelts B, Brück C, Nizielski S, Schütz A, Wildgruber D. Nonverbal signals speak up: association between perceptual nonverbal dominance and emotional intelligence. Cogn Emot (2013a) 27(5):783-99. doi: 10.1080/02699931.2012.739999

38. Ambady N, Bernieri FJ, Richeson JA. Toward a histology of social behavior: judgmental accuracy from thin slices of the behavioral stream. In: Zanna MP, editor. Advances in experimental social psychology. United States: Academic Press (2000). p. 201-71. doi: 10.1016/S0065-2601(00)80006-4

39. Silverman J, Kinnersley P. Doctors' non-verbal behaviour in consultations: look at the patient before you look at the computer. Br J Gen Pract (2010) 76-8. doi: 10.3399/bjgp10X482293

40. Ambady N, Gray HM. On being sad and mistaken: mood effects on the accuracy of thin-slice judgments. J Pers Soc Psychol (2002) 83(4):947. doi: 10.1037/0022-3514.83.4.947

41. Gilbert DT, Krull DS. Seeing less and knowing more: the benefits of perceptual ignorance. J Pers Soc Psychol (1988) 54(2):193. doi: 10.1037/0022-3514.54.2.193

42. Patterson ML, Stockbridge E. Effects of cognitive demand and judgment strategy on person perception accuracy. J Nonverbal Behav (1998) 22(4):25363. doi: 10.1023/A:1022996522793

43. Calder AJ, Beaver JD, Winston JS, Dolan RJ, Jenkins R, Eger E, et al. Separate coding of different gaze directions in the superior temporal sulcus and inferior parietal lobule. Curr Biol (2007) 17(1):20-5. doi: 10.1016/ j.cub.2006.10.052

44. Howe LC, Goyer JP, Crum AJ. Harnessing the placebo effect: exploring the influence of physician characteristics on placebo response. Health Psychol (2017) 36(11):1074. doi: 10.1037/hea0000499

45. Oliveira VC, Refshauge KM, Ferreira ML, Pinto RZ, Beckenkamp PR, Negrao Filho RF, et al. Communication that values patient autonomy is associated with satisfaction with care: a systematic review. J Physiother (2012) 58(4):215-29. doi: 10.1016/S1836-9553(12)70123-6

46. Egbert LD, Battit GE, Welch CE, Bartlett MK. Reduction of postoperative pain by encouragement and instruction of patients: a study of doctorpatient rapport. $N$ Eng J Med (1964) 270(16):825-7. doi: 10.1056/ NEJM196404162701606

47. Otto MW, Dougher MJ. Sex differences and personality factors in responsivity to pain. Percept Mot Skills (1985) 61(2):383-90. doi: 10.2466/ pms.1985.61.2.383

48. Feine JS, Bushnell MC, Miron D, Duncan GH. Sex differences in the perception of noxious heat stimuli. Pain (1991) 44(3):255-62. doi: 10.1016/0304-3959(91)90094-E

49. Bush FM, Harkins SW, Harrington WG, Price DD. Analysis of gender effects on pain perception and symptom presentation in temporomandibular pain. Pain (1993) 53(1):73-80. doi: 10.1016/0304-3959(93)90058-W

50. Fillingim RB, Edwards RR, Powell $T$. The relationship of sex and clinical pain to experimental pain responses. Pain ${ }^{\circledR}$ (1999) 83(3):419-25. doi: 10.1016/ S0304-3959(99)00128-1

51. Carter LE, McNeil DW, Vowles KE, Sorrell JT, Turk CL, Ries BJ, et al. Effects of emotion on pain reports, tolerance and physiology. Pain Res Manage (2002) 7(1):21-30. doi: 10.1155/2002/426193

52. Thorn BE, Clements KL, Ward LC, Dixon KE, Kersh BC, Boothby JL, et al. Personality factors in the explanation of sex differences in pain catastrophizing and response to experimental pain. Clin J Pain (2004) 20(5):275-82. doi: 10.1097/00002508-200409000-00001

53. Essick G, Guest S, Martinez E, Chen C, Mcglone F. Site-dependent and subject-related variations in perioral thermal sensitivity. Somatosens Mot Res (2004) 21(3-4):159-75. doi: 10.1080/08990220400012414
54. Gijsbers K, Nicholson F. Experimental pain thresholds influenced by sex of experimenter. Percept Mot Skills (2005) 101(3):803-7. doi: 10.2466/ pms.101.3.803-807

55. Williams DA, Park KM, Ambrose KR, Clauw DJ. Assessor status influences pain recall. J Pain (2007) 8(4):343-8. doi: 10.1016/j.jpain.2006.10.005

56. Aslaksen PM, Flaten MA. The roles of physiological and subjective stress in the effectiveness of a placebo on experimentally induced pain. Psychosom Med (2008) 70(7):811-8. doi: 10.1097/PSY.0b013e31818105ed

57. Kaptchuk TJ, Kelley JM, Conboy LA, Davis RB, Kerr CE, Jacobson EE, et al. Components of placebo effect: randomised controlled trial in patients with irritable bowel syndrome. Bmj (2008) 336(7651):999-1003. doi: 10.1136/ bmj.39524.439618.25

58. Weimer K, Schulte J, Maichle A, Muth ER, Scisco JL, Horing B, et al. Effects of ginger and expectations on symptoms of nausea in a balanced placebo design. PLoS One (2012) 7(11):e49031. doi: 10.1371/journal.pone.0049031

59. Vigil JM, Rowell LN, Alcock J, Maestes R. Laboratory personnel gender and cold pressor apparatus affect subjective pain reports. Pain Res Manage (2014) 19(1):e13-8. doi: 10.1155/2014/213950

60. Vigil JM, Alcock J. Tough guys or sensitive guys? Disentangling the role of examiner sex on patient pain reports. Pain Res Manage (2014) 19(1):e9-12. doi: $10.1155 / 2014 / 531396$

61. Sorge RE, Martin LJ, Isbester KA, Sotocinal SG, Rosen S, Tuttle AH, et al. Olfactory exposure to males, including men, causes stress and related analgesia in rodents. Nat Methods (2014) 11(6):629. doi: 10.1038/nmeth.2935

62. Vigil JM, DiDomenico J, Strenth C, Coulombe P, Kruger E, Mueller AA, et al. Experimenter effects on pain reporting in women vary across the menstrual cycle. Int J Endocrinol (2015) 2015:1-8. doi: 10.1155/2015/520719

63. Gryll SL, Katahn M. Situational factors contributing to the placebo effect. Psychopharmacology (1978) 57(3):253-61. doi: 10.1007/BF00426747

64. Brown JL, Sheffield D, Leary MR, Robinson ME. Social support and experimental pain. Psychosom Med (2003) 65(2):276-83. doi: 10.1097/01. PSY.0000030388.62434.46

65. Verheul W, Sanders A, Bensing J. The effects of physicians' affect-oriented communication style and raising expectations on analogue patients' anxiety, affect and expectancies. Patient Educ Couns (2010) 80(3):300-6. doi: 10.1016/j.pec.2010.06.017

66. Modić Stanke K, Ivanec D. Social context of pain perception: the role of other people's presence and physical distance. Rev Psychol (2010) 17(1):69-74. https://hrcak.srce.hr/70663

67. Bohns VK, Wiltermuth SS. It hurts when I do this (or you do that): posture and pain tolerance. J Exp Soc Psychol (2012) 48(1):341-5. doi: 10.1016/ j.jesp.2011.05.022

68. Valentini E, Martini M, Lee M, Aglioti SM, Iannetti G. Seeing facial expressions enhances placebo analgesia. Pain ${ }^{\circledR}$ (2014) 155(4):666-73. doi: 10.1016/j.pain.2013.11.021

69. Ruben MA, Hall JA. Healthcare providers' nonverbal behavior can lead patients to show their pain more accurately: an analogue study. J Nonverbal Behav (2016) 40(3):221-34. doi: 10.1007/s10919-016-0230-3

70. Ruben MA, Blanch-Hartigan D, Hall JA. Nonverbal communication as a pain reliever: the impact of physician supportive nonverbal behavior on experimentally induced pain. Health Commun (2016) 32(8):970-6. doi: 10.1080/10410236.2016.1196418

71. Czerniak E, Biegon A, Ziv A, Karnieli-Miller O, Weiser M, Alon U, et al. Manipulating the placebo response in experimental pain by altering doctor's performance style. Front Psychol (2016) 7:874. doi: 10.3389/fpsyg.2016.00874

72. Van Osch M, van Dulmen S, van Vliet L, Bensing J. Specifying the effects of physician's communication on patients' outcomes: a randomised controlled trial. Patient Educ Couns (2017) 100(8):1482-9. doi: 10.1016/j. pec.2017.03.009

73. He X, Sun Q, Stetler C. Warm communication style strengthens expectations and increases perceived improvement. Health Commun (2018) 33(8):93945. doi: $10.1080 / 10410236.2017 .1322482$

74. Drucker AM, Fleming P, Chan AW. Research techniques made simple: assessing risk of bias in systematic reviews. J Invest Dermatol (2016) 136(11):e109-14. doi: 10.1016/j.jid.2016.08.021

75. Higgins JP, Altman DG, Gøtzsche PC, Jüni P, Moher D, Oxman AD, et al. The Cochrane Collaboration's tool for assessing risk of bias in randomised trials. $\operatorname{Bmj}$ (2011) 343:d5928. doi: 10.1136/bmj.d5928 
76. Kim SY, Park JE, Lee YJ, Seo HJ, Sheen SS, Hahn S, et al. Testing a tool for assessing the risk of bias for nonrandomized studies showed moderate reliability and promising validity. J Clin Epidemiol (2013) 66(4):408-14. doi: 10.1016/j.jclinepi.2012.09.016

77. Geary DC, Vigil J, Byrd-Craven J. Evolution of human mate choice. J Sex Res (2004) 41(1):27-42. doi: 10.1080/00224490409552211

78. Ghione S. Hypertension-associated hypalgesia: evidence in experimental animals and humans, pathophysiological mechanisms, and potential clinical consequences. Hypertension (1996) 28(3):494-504. doi: 10.1161/01. HYP.28.3.494

79. France CR. Decreased pain perception and risk for hypertension: considering a common physiological mechanism. Psychophysiology (1999) 36(6):683-92. doi: 10.1111/1469-8986.3660683

80. Brody S, Rau H. Behavioral and psychophysiological predictors of selfmonitored 19 month blood pressure change in normotensives. J Psychosom Res (1994) 38(8):885-91. doi: 10.1016/0022-3999(94)90075-2

81. Droste C, Kardos A, Brody S, Greenlee MW, Roskamm H, Rau H. Baroreceptor stimulation: pain perception and sensory thresholds. Biol Psychol (1994) 37(2):101-13. doi: 10.1016/0301-0511(94)90025-6

82. Dworkin BR, Elbert T, Rau H, Birbaumer N, Pauli P, Droste C, et al. Central effects of baroreceptor activation in humans: attenuation of skeletal reflexes and pain perception. Proc Natl Acad Sci (1994) 91(14):6329-33. doi: 10.1073/ pnas.91.14.6329

83. Rau H, Brody S, Larbig W, Pauli P, Vöhringer M, Harsch B, et al. Effects of PRES baroreceptor stimulation on thermal and mechanical pain threshold in borderline hypertensives and normotensives. Psychophysiology (1994) 31(5):480-5. doi: 10.1111/j.1469-8986.1994.tb01051.x
84. Edwards L, Ring C, McIntyre D, Carroll D. Modulation of the human nociceptive flexion reflex across the cardiac cycle. Psychophysiology (2001) 38(4):712-8. doi: 10.1111/1469-8986.3840712

85. Edwards L, McIntyre DA, Carroll D, Ring C, Martin U. The human nociceptive flexion reflex threshold is higher during systole than diastole. Psychophysiology (2002) 39(5):678-81. doi: 10.1111/1469-8986.3950678

86. Rosenthal R, Rubin DB. Interpersonal expectancy effects: the first 345 studies. Behav Brain Sci (1978) 1(3):377-86. doi: 10.1017/S0140525X00075506

87. Flaten MA, Bjørkedal E, Lyby PS, Figenschau Y, Aslaksen PM. Failure to find a conditioned placebo analgesic response. Front Psychol (2018) 9. doi: 10.3389/fpsyg.2018.01198

88. Jacob H, Brück C, Domin M, Lotze M, Wildgruber D. I can't keep your face and voice out of my head: neural correlates of an attentional bias toward nonverbal emotional cues. Cereb Cortex (2013b) 24(6):1460-73. doi: $10.1093 /$ cercor/bhs417

Conflict of Interest Statement: The authors declare that the research was conducted in the absence of any commercial or financial relationships that could be construed as a potential conflict of interest.

Copyright (C) 2019 Daniali and Flaten. This is an open-access article distributed under the terms of the Creative Commons Attribution License (CC BY). The use, distribution or reproduction in other forums is permitted, provided the original author(s) and the copyright owner(s) are credited and that the original publication in this journal is cited, in accordance with accepted academic practice. No use, distribution or reproduction is permitted which does not comply with these terms. 